\title{
Vitamin D Deficiency in Premature Infants and Its Effects on Neonatal Prognosis
}

\author{
(1) Demet Terek, (1) Gizem Özcan, (1) Fırat Ergin, (1) Özge Altun Köroğlu, (1) Mehmet Yalaz, \\ (1) Mete Akisu, (1) Nilgün Kültürsay \\ Ege University Faculty fo Medicine, Department of Pediatrics, Division of Neonatology, Izmir, Turkey
}

\begin{abstract}
Aim: In the present study, the relationship between neonatal morbidity and cord vitamin $D$ levels is investigated.

Materials and Methods: Premature infants who were born before 32 weeks of gestation and admitted to our neonatal intensive care unit between January 2014 and January 2015 were included in the study. Vitamin D levels in the cord blood of infants were measured. Serum calcium, phosphorus and alkaline phosphatase levels were recorded in the first 24 hours. All neonates were followed up for neonatal morbidities until discharge.

Results: The mean gestational age of the study subjects was $29.2 \pm 2.6$ (23-32). The mean vitamin D level was $27.4 \pm 19.3 \mathrm{ng} / \mathrm{mL}(4-76)$. Fourteen (46.7\%) infants had normal vitamin D levels; 2 infants (6.7\%) had vitamin D insufficiency (20-30 ng/mL), 14 infants (46.7\%) had vitamin D deficiency ( $20 \mathrm{ng} / \mathrm{mL})$, and 7 infants had severe vitamin D deficiency $(23.3 \%)$. In $60 \%$ of infants with intrauterine growth restriction had vitamin $D$ deficiency of $p<0.05$. Serum phosphorus levels on the first day of life were significantly lower in infants with vitamin $\mathrm{D}$ deficiency $(\mathrm{p}<0.001)$.

Conclusion: In more than half of the study population vitamin $\mathrm{D}$ deficiency was determined. Infants with intrauterine growth restriction had vitamin $\mathrm{D}$ deficiency in more than half of the cases. Low levels of phosphorus may be a marker of vitamin $D$ deficiency in the first days of life.

Keywords: Preterm birth, vitamin D, intrauterine growth restriction
\end{abstract}

\section{Introduction}

The importance of vitamin D as a modulator of calcium and bone metabolism is well known (1), and it is also involved in the innate immune system, cell proliferation and neuromuscular functions (2-4). Vitamin $D$ is reported to inhibit the nuclear factor-kappa beta pathway and reduce inflammation in decidua (5). Recently, vitamin $D$ has been suggested to be involved in the pathogenesis of many diseases such as cancer, multiple sclerosis, diabetes and cardiovascular disease via cell proliferation and immune function (6). Vitamin D deficiency in newborns is related to neonatal sepsis and respiratory system infections. Maternal vitamin $\mathrm{D}$ deficiency increases the risk of premature delivery, preeclampsia, gestational diabetes mellitus and intrauterine growth restriction (7-9). These perinatal complications trigger preterm delivery and these premature infants have a greater risk of vitamin $D$ deficiency. Studies have shown that vitamin $\mathrm{D}$ deficiency is more prominent in the second and third trimesters. The rate of premature delivery is $8-12 \%$ in the world and results in fetal morbidity and mortality (10). Considering the wide distribution of vitamin $D$ receptors and its newly suggested roles in many adult diseases, particularly those associated with inflammatory pathways, it may also be involved in neonatal morbidities related to immature immune system and inflammation. Furthermore, early recognition of vitamin $D$ deficiency makes early and appropriate supplementation possible to prevent the increased risk of possible vitamin D related morbidities. Thus, in this study cord blood vitamin $D$ levels were measured 
so as to determine the rate of Vitamin D deficiency in very preterm newborns ( $<32$ weeks) and to illuminate its relation with neonatal morbidities.

\section{Materials and Methods}

Premature infants with gestational ages below 32 weeks who were born in the University Hospital and admitted to the neonatal intensive care unit NICU between January 2014 and January 2015 were enrolled in the study. Patients with cyanotic heart disease, chromosomal anomalies, and congenital anomalies were excluded from the study. This study was approved by the Ege University Faculty of Medicine Clinical Research Ethics Committee (approval number: 11-12.2/4). The parents provided informed consent for the study.

\section{Assessment of Blood Vitamin D Levels}

Vitamin D levels were measured in the cord blood of the infants. Serum calcium, phosphorus and alkaline phosphatase (ALP) levels were measured in the first 24 hours. Serum 25-hydroxyvitamin D3 [25(OH)D3] level lower than $20 \mathrm{ng} / \mathrm{mL}$ is defined as vitamin D deficiency. Serum $25(\mathrm{OH}) \mathrm{D} 3$ level lower than $10 \mathrm{ng} / \mathrm{mL}$ is defined as severe vitamin D deficiency. Serum 25(OH)D3 level between 20-30 $\mathrm{ng} / \mathrm{mL}$ is defined as insufficient vitamin $\mathrm{D}(10)$.

\section{Maternal and Neonatal Demographic and Clinical Data}

Detailed antenatal history including maternal age, gestational week, mode of delivery, number of live births, history of preeclampsia, diabetes mellitus, and premature rupture of membranes, was recorded. All the premature infants were prospectively followed for neonatal morbidities (Respiratory Distress syndrome [RDS]), sepsis, pneumonia, bronchopulmonary dysplasia (BPD), necrotizing enterocolitis (NEC), intraventricular hemorrhage, mortality and the duration of mechanical ventilation. Clinical sepsis is defined as documentation of infection with a serious systemic illness in which non-infectious explanations for the abnormal pathophysiological state are excluded or unlikely. By definition, in early clinical sepsis clinical signs appear in the first 5 days and in late sepsis $>5$ days (11). RDS is diagnosed clinically with early respiratory distress manifested with cyanosis, grunting, retractions and tachypnea. The diagnosis is confirmed with blood gas analysis and chest X-ray with a classical "ground glass" appearance and air bronchograms (12). BPD is defined according to universal guidelines in infants with prolonged oxygen requirement and accompanying radiological changes (13). NEC is the mucosal ischemic necrosis of the intestines. Staging defined by Schanler et al. (14) is used. Intraventricular bleeding is classified according to Papile classification (15).

\section{Statistical Analysis}

SPSS 16.0 (SPSS, Chicago, IL) was used for statistical analysis. The stastitical analyses were performed in Ege University Bioistatistics Unit. Data were expressed as mean and standard deviation. Differences between the two groups were analyzed by Student t-test or Mann-Whitney $U$ test, where appropriate. Pearson test was used to analyze the correlation between variables. $p$ value of $<0.05$ was accepted as significant.

\section{Results}

The mean gestational week of the study population was $29.2 \pm 2.6$ (23-32), the mean birth weight was $1331 \pm 414$ (6202815) grams (Table I). In antenatal history preeclampsia rate was $20 \%(n=6)$ and intrauterine growth restriction rate was $16.7 \%(n=5)$ (Table I). In clinical follow-up, the rate of RDS was $46.3 \%(n=14)$, sepsis $50 \%(n=15)$, pneumonia $16.7 \%$ $(n=5), \operatorname{BPD} 25 \%(n=7), N E C 10 \%(n=3)$, intraventricular bleeding $36 \%(n=11)$ and mortality was $16.7 \%(n=5)$. The mean vitamin D level was $27.4 \pm 19.3 \mathrm{ng} / \mathrm{mL}$ (4-76). Vitamin D level was normal in 14 cases (46.7\%). Vitamin D insufficiency was present in two cases (6.7\%) while 14 cases $(46.7 \%)$ had vitamin D deficiency. Severe vitamin D deficiency was seen in 7 cases (23.3\%) (Table II). Gestational age and birth weights of infants with or without vitamin D deficiency were similar. However, intrauterine growth restriction was present in $42 \%$ of cases with $25(\mathrm{OH}) \mathrm{D}$ level lower than $10 \mathrm{ng} / \mathrm{mL}$. Intrauterine growth restriction was present in $8.7 \%$ of cases with $25(\mathrm{OH}) \mathrm{D}$ level greater than $10 \mathrm{ng} / \mathrm{mL}$. In $60 \%$ of cases with intrauterine growth restriction vitamin D level was $\leq 20 \mathrm{ng} / \mathrm{mL}(\mathrm{p}<0.05)$. There was no correlation between vitamin $\mathrm{D}$ deficiency and premature rupture of membranes, neonatal sepsis, respiratory distress, NEC, BPD, intraventricular bleeding and mortality. On the first day of life, the mean calcium level was $8.3 \pm 0.8 \mathrm{mg} / \mathrm{dL}$. and the mean phosphorus level was $4.6 \pm 1.46 \mathrm{mg} / \mathrm{dL}$. In cases with vitamin $D$ deficiency, the mean phosphorus level was significantly lower $(p<0.001)$ (Table III).

\begin{tabular}{|l|l|}
\hline \multicolumn{2}{|l|}{ Table I. Demographic data } \\
\hline Mean gestational age & $30 \pm 2.9$ \\
\hline Mean birth weight & $1335 \pm 414$ \\
\hline Female/male ratio & $12 / 18$ \\
\hline Rate of preeclampsia & $6 / 30(20 \%)$ \\
\hline Rate of gestational diabetes mellitus & $2 / 30(6.7 \%)$ \\
\hline Rate of premature rupture of membranes & $5 / 30(16.6 \%)$ \\
\hline Delivery mode & C section 23/30 vaginal $7 / 30$ \\
\hline
\end{tabular}

\begin{tabular}{|l|l|}
\hline \multicolumn{2}{|l|}{ Table II. Vitamin D levels of cases } \\
\hline 25(OH)D level & Distribution of cases $(\mathbf{n} / \%)$ \\
\hline$>30(\mathrm{ng} / \mathrm{mL})$ & $14(46.7)$ \\
\hline $20-30(\mathrm{ng} / \mathrm{mL})$ & $2(6.7)$ \\
\hline$\leq 20(\mathrm{ng} / \mathrm{mL})$ & $14(46.7)$ \\
\hline$\leq 10(\mathrm{ng} / \mathrm{mL})$ & $7(23.3)$ \\
\hline
\end{tabular}

25(OH)D: 25-hydroxyvitamin D 


\begin{tabular}{|c|c|c|c|}
\hline & $\begin{array}{l}\text { Vitamin D } \\
>20 \mathrm{ng} / \mathrm{mL}\end{array}$ & $\begin{array}{l}\text { Vitamin D } \\
\leq 20 \mathrm{ng} / \mathrm{mL}\end{array}$ & $p$ value \\
\hline Mean calcium & $8.5 \pm 0.7 \mathrm{mg} / \mathrm{dL}$ & $8.2 \pm 0.8 \mathrm{mg} / \mathrm{dL}$ & 0.44 \\
\hline Mean phosphorus & $5.1 \pm 0.8 \mathrm{mg} / \mathrm{dL}$ & $3.3 \pm 0.8 \mathrm{mg} / \mathrm{dL}$ & 0.001 \\
\hline Mean ALP & $168 \pm 70 \mathrm{IU} / \mathrm{L}$ & $164 \pm 50 \mathrm{IU} / \mathrm{L}$ & 0.80 \\
\hline
\end{tabular}

ALP: Alkaline phosphatase

\section{Discussion}

Vitamin D deficiency is a worldwide problem and yet it is a preventable disease. Umbilical cord vitamin $\mathrm{D}$ level is correlated with maternal serum vitamin D level. Also, in fetal and neonatal period vitamin $\mathrm{D}$ level correlates with maternal serum level of vitamin D. During pregnancy if the mother has a vitamin $D$ deficiency, fetuses carry a significant risk of vitamin $D$ deficiency. The rate of vitamin $D$ deficiency in premature infants is reported to be $64 \%$ in the United States of America, $83 \%$ in India, $63.7 \%$ in France. In a study from Australia, vitamin D levels in cord blood was $<20 \mathrm{ng} / \mathrm{mL}$ in $40 \%$ of infants (16). There are limited studies on neonatal vitamin D levels in our country; and most data are obtained from studies in children. Ataseven et al. (17) from Middle Black Sea, examined 152 preterms with gestational ages 29-35 weeks. They found severe vitamin $D$ deficiency in $64 \%$. Serum $25(\mathrm{OH}) \mathrm{D} 3$ is a very good marker of vitamin D level in the blood. In our study the mean $25(\mathrm{OH}) \mathrm{D}$ level was $27.4 \pm 19.3 \mathrm{ng} / \mathrm{mL}$ (4-76). Vitamin D level was normal in 14 cases $(46.7 \%)$. Vitamin D insufficiency was present in two cases $(6.7 \%)$, and vitamin D deficiency was seen in 14 cases (46.7\%). Severe vitamin D deficiency was present in 7 cases (23.3\%). Burris et al. (18) reported umbilical cord 25(OH)D level of $34 \mathrm{ng} / \mathrm{mL}$ in their study including term and preterm infants. In their study $40 \%$ of the newborns had vitamin D levels lower than $30 \mathrm{ng} / \mathrm{mL}$ and $14.4 \%$ had vitamin D levels lower than $20 \mathrm{ng} / \mathrm{mL}$. In the same study population $25 \%$ of the newborns born before 32 weeks of gestation had vitamin $\mathrm{D}$ levels lower than $20 \mathrm{ng} / \mathrm{mL}$. In our study the mean vitamin $\mathrm{D}$ level was lower and vitamin D deficiency rates were higher when compared to Burris study.

In another study the mean vitamin $D$ level in premature infants was $16.3 \mathrm{ng} / \mathrm{mL}$ (19). Park et al. (20) found vitamin D level as $10.7 \pm 6.4 \mathrm{ng} / \mathrm{mL}$ in a study of 278 cases with a mean gestational age of $33 \pm 2$ weeks. In the cohort of Park et al. (20) $91 \%$ of newborn babies have vitamin D deficiency and there is severe vitamin D deficiency in $51 \%$. In our study the mean vitamin $D$ level was higher and vitamin $D$ deficiency rates were lower when compared to the above studies $(19,20)$. In our study, vitamin D levels were not related to gestational age and birth weight. Burris et al. (18) did not see any linear correlation between vitamin D level and gestational week. Park et al. (20) reported insignificant correlation of vitamin $\mathrm{D}$ levels with gestational age and birth weight.
We did not observe any correlation of vitamin $D$ levels and the presence of premature rupture of membrane. In our cases with intrauterine growth restriction vitamin $D$ level was $\leq 20 \mathrm{ng} / \mathrm{mL}$ in $60 \%$ of cases $(\mathrm{p}<0.05)$. Low maternal vitamin $D$ levels during pregnancy also have been shown to be associated with increased risk of specific conditions including gestational diabetes, preeclampsia and poor fetal growth (20). Park et al. (20) reported insignificant correlation of vitamin $D$ levels with premature rupture of membranes and preeclampsia, and a small correlation with gestational age. Wei et al. $(8,9)$ reported a higher risk of preterm delivery, preeclampsia, gestational diabetes mellitus in maternal vitamin D deficiency. In our study the striking finding is the lower vitamin D level in the newborns with intrauterine growth restriction. We found no correlation between vitamin $\mathrm{D}$ deficiency and neonatal sepsis, respiratory distress, NEC, intraventricular bleeding and mortality. Onwuneme et al. (21) reported no significant statistical correlation between vitamin D level and respiratory distress, NEC, intraventricular bleeding, sepsis and mortality in 94 preterm infants under the gestational age of 32 weeks. But Fettah et al. (22) found significantly increased respiratory distress risk in infants with vitamin D levels lower than $15 \mathrm{ng} / \mathrm{mL}$. In our study, on the first day of life, the mean calcium level was $8.3 \pm 0.8 \mathrm{mg} / \mathrm{dL}$ and the mean phosphorus level was $4.6 \pm 1.46 \mathrm{mg} / \mathrm{dL}$. In cases with vitamin $\mathrm{D}$ deficiency, the mean phosphorus level was significantly lower. In similar studies in the literature, serum calcium and phosphorus levels do not change significantly; however, there is prominent increase in ALP levels (20).

\section{Study Limitation}

There is not enaught number of cases.

\section{Conclusion}

Vitamin D deficiency was present in more than half of the study population. Vitamin D deficiency was encountered more often in intrauterine growth restricted fetuses. The low phosphorus level on the first day of life may be a marker of vitamin $D$ deficiency. More studies are needed with larger populations of premature infants to clarify the complex interactions of vitamin D.

\section{Ethics}

Ethics Committee Approval: This study was approved by the Ege University Faculty of Medicine Clinical Research Ethics Committee (approval number: 11-12.2/4).

Informed Consent: The parents provided informed consent for the study.

Peer-review: Externally peer-reviewed.

\section{Authorship Contributions}

Medical Practices: N.K., M.Y., Concept: Ö.A.K., M.A., Design: Ö.K., D.T., M.Y., Data Collection or Processing: D.T., G.Ö., Analysis or Interpretation: D.T., M.Y., Literature Search: D.T., F.E., Writing: N.K., Ö.K., D.T. 
Conflict of Interest: No conflict of interest was declared by the authors.

Financial Disclosure: The authors declared that this study received no financial support.

\section{References}

1. Goodman WG. The flavors of vitamin D: tasting the molecular mechanism. Kidney Int. 2004;66:1286-7.

2. Lappe JM, Travers-Gustafson D, Davies KM, Recker RR, Heaney RP. Vitamin D and calcium supplementation reduces cancer risk: results of a randomized trial. Am J Clin Nutr 2007;85:1586-91

3. Yang S, Smith C, Prahl JM, Luo X, DeLuca HF Vitamin D deficiency suppresses cell- mediated immunity in vivo. Arch Biochem Biophys 1993;303:98-106.

4. Chen S, Sims GP, Chen XX, Gu YY, Chen S, Lipsky PE. Modulatory effects of 1,25 vitamin D3 on human B cell differentiation. J Immunol 2007:179:1634-47.

5. Cohen- Lahav M, Shany S, Tobvin D, Chaimovitz C Douvdevani A. Vitamin D decreases NFkappaB activity by increasing IkappaBalpha levels. Nephrol Dial Transplant 2006;21:889-97

6. Valdivielso JM, Fernandez E. Vitamin D receptor polymorphisms and diseases. Clin Chim Acta 2006;371:112.

7. Shin $\mathrm{YH}, \mathrm{Yu}$ J, Kim KW, et al. Association between cord blood 25-hydroxyvitamin D concentrations and respiratory tract infections in the first 6 months of age in a Korean population: a birth cohort study (COCOA) Korean. J Pediatr 2013;56:439-45.

8. Wei SQ, Qi HP, Luo ZC, Fraser WD. Maternal vitamin D status and adverse pregnancy outcomes: a systematic review and meta-analysis. J Matern Fetal neonatal Med 2013;26:889-99.

9. Wei SQ. Vitamin D and pregnancy outcomes. Curr Opin Obstet Gynecol 2014;26:438-47.

10. Woythaler MA, Mc Cormic MC, Smith VC. Late preterm infants have worse 24 month neurodevelopmental outcomes than term infants. Pediatrics 2011;127:622-9.
11. Chiesa C, Panero A, Osborn JF, Simonetti AF, Pacifico L. Diagnosis of neonatal sepsis: A clinical and laboratory challenge. Clin Chem 2004;50:279-87.

12. Sweet DG, Carnielli V, Greisen G, et al. European consensus guidelines on the management of neonatal respiratory distress syndrome in preterm infants - 2010 update. Neonatology 2010;97:402-17.

13. Jobe $A H$, Bancalari E. Bronchopulmonary dysplasia. Am J Respir Crit Care Med 2001;163:1723-9.

14. Schanler RJ. Clinical features and diagnosis of necrotizing enterocolitis in newborns. In Up to date, Abrams SA, 2015.

15. Papil LA, Burstein J, Burstein R, Koffler H. Incidence and evolution of subependymal and intraventricular hemorrhage: a study of infants with birth weights less than $1,500 \mathrm{gm}$. J Pediatr 1978;92:529-34.

16. Monangi H, Slaughter JL, Dawodu A, Smith C, Akinbi HT. Vitamin D status of early preterm infants and the effects of vitamin $\mathrm{D}$ intake during hospital stay. Arc Dis Child Fetal Neonatal Ed 2014;99:166-8.

17. Ataseven $F$, Aygün $C$, Okuyucu $A$, Bedir $A$, Kücük $Y$, Kücüködük $S$. Is vitamin $D$ deficiency a risk factor for respiratory distress syndrome ? Int J Vitam Nur Res 2013;83:232-7.

18. Burris $H H$, Van Marter LJ, McElrath $T F$, et al. Vitamin D status among preterm and full-term infants at birth. Pediatr Res 2014;75:75-80.

19. Dawodu A, Nath R. High prevalence of moderately severe vitamin $D$ deficiency in preterm infants. Pediatr Int 2011;53:207-10.

20. Park SH, Lee GM, Moon JE, Kim HM. Severe vitamin D deficiency in preterm infants: maternal and neonatal clinical features. Korean J Pediatr 2015;58:427-33.

21. Onwuneme C, Martin F, McCarthy R, et al. The Association of Vitamin D Status with Acute Respiratory Morbidity in Preterm Infants. J Pediatr 2015;166:1175-80.

22. Fettah ND, Zenciroğli $A$, Dilli $D$, Beken $S$, Okumuş N. Is Higher 25-Hydroxyvitamin D Level Preventive for Respiratory Distress Syndrome in Preterm Infants? Am J Perinatol 2015;32:247-50. 